\title{
Structure formation of high-chromium cast irons in the temperature range of the magnetic transformation of carbide phases
}

\author{
T. S. Skoblo, O. Yu. Klochko ${ }^{\dagger}$ E. L. Belkin, A. I. Sidashenko, V. K. Avetisyan \\ †klochko.hntysh@gmail.com
}

Kharkiv Petro Vasylenko National Technical University of Agriculture, 44 Alchevs 'kikh St., Kharkiv, 61002, Ukraine

\begin{abstract}
A new comprehensive approach has been developed to characterize the structure formation of high-chromium cast iron in the working layers of mill rolls (10-12 tons weight) within the hot finishers. Application of our approach makes it possible to estimate the phase composition of the alloy. Such heterogeneous material is characterized by insufficient stability of properties and the absence of reliable methods for assessing structure formation. The structural features of massive castings (up to 20 tons) are revealed in the process of crystallization and operation under the temperatures of magnetic transformation of the carbide phases (magnetostriction phenomenon). The conducted studies introduce a new understanding of the phase composition of high chromium cast iron, the phase composition variability at magnetic transformation of carbide phases and decomposition of retained austenite. The variability of phases and their interconnection during casting and heat treatment are estimated. It has been shown that photographs of metallographic images do not allow one to reliably estimate the alloy phase composition, since the primary image pattern after crystallization preserves, while a partial phase decomposition with the formation of their various combinations takes place. The possibility of accurate qualitative and quantitative identification of the formed phases in the cast and heat-treated state in a multiphase heterogeneous alloy (high-chromium cast iron of large masses) is shown. A new approach to the characterization of structure formation in a multiphase alloy with the opticalmathematical method for the description of metallographic images is proposed. We show that the insufficient stability of the phase composition while casting under magnetostriction temperatures and with the proposed effective heat treatment method used is determined by the variability of structure formation with the buildup of certain bonds between the phases and decomposition of residual austenite.
\end{abstract}

Keywords: high-chromium cast iron, massive castings, magnetic transformation of carbide phases, residual austenite, composition and interrelation of phases.

УДК: 669.1.017:51-74

\section{Структурообразование высокохромистых чугунов}

\section{в интервале температур магнитного превращения карбидных фаз}

\author{
Скобло Т. С., Клочко О.Ю.†, Белкин Е. Л., Сидашенко А. И., Аветисян В.К. \\ Харьковский национальный технический университет сельского хозяйства им. Петра Василенко, \\ ул. Алчевских, 44, Харьков, 61002, Украина
}

Разработан и использован новый комплексный подход оценки структурообразования высокохромистого чугуна для рабочего слоя прокатных валков массой 10-12 т для чистовых клетей листовых станов горячей прокатки, что позволило получить представление о фазовом составе сплава. Такой гетерогенный материал характеризуется недостаточной стабильностью свойств и отсутствием надежных методов оценки структурообразования. Выявлены особенности структурообразования массивных отливок (до 20 т) при их кристаллизации и обработке в интервале температур магнитного превращения карбидных фаз (явление магнитострикции). В выполненных исследованиях получено новое представление о фазовом составе высокохромистого чугуна, его изменчивости при магнитном превращении карбидных фаз, распаде остаточного аустенита. Оценена изменчивость фаз и их взаимосвязь при литье и термообработке. Показано, что фотографии металлографических изображений не позволяют 
надежно оценить фазовый состав сплава, поскольку первичный рельеф изображения после их кристаллизации сохраняется, а по существу в нем происходит частичный распад фаз с формированием их различных сочетаний. Показана возможность точной качественной и количественной идентификации формируемых фаз в литом и термообработанном состоянии в многофазном гетерогенном сплаве - высокохромистом чугуне отливок большой массы. Предложен новый подход к оценке структурообразования в многофазном сплаве с использованием оптикоматематического метода описания металлографических изображений. Выполненные исследования показали, что недостаточная стабильность фазового состава при литье и предложенном эффективном методе термообработки в интервале температур магнитного превращения карбидов определяются изменчивостью структурообразования с формированием и определенных взаимосвязей между фазами, а также распадом остаточного аустенита.

Ключевые слова: высокохромистый чугун, массивные отливки, магнитное превращение карбидных фаз, остаточный аустенит, состав и взаимосвязь фаз.

\section{1. Введение}

Высокохромистые чугуны находят широкое применение в металлургии и машиностроении. Их используют для изготовления прокатных валков, лопаток турбин и других изделий. Такой материал отличается высокой эксплуатационной стойкостью, однако для изготовления массивных изделий, таких как прокатные валки массой до 20 т, является нетехнологичным в изготовлении. Поэтому при производстве таких изделий высокохромистый чугун используют только для их рабочего слоя сечением до 40 мм при центробежном методе литья. Недостатком этого материала при использовании в таких изделиях является кристаллизация значительной доли остаточного аустенита, который при эксплуатации, под воздействием значительных удельных давлений до 3 т/мм² и повышенной температуры от контакта с прокатываемым металлом, распадается с формированием локальных напряжений и зарождением повреждаемости на поверхности рабочего слоя - сетки разгара и выкрашиваний. Проведение термообработки таких изделий при высокой температуре и даже более низкой (отжиг $600^{\circ} \mathrm{C}$ ) в течение длительного периода времени [1-3] является технически сложным и нецелесообразным из-за повышенной склонности к графитизации серого чугуна, который используют для сердцевины и шеек.

Исследованиями [4-6] было показано, что в интервале температур магнитного превращения карбидов различного типа и степени их легированности $\left(190-500^{\circ} \mathrm{C}\right)$ отмечается падение прочности при сохранении уровня твердости [6], которая является основной, нормируемой стандартом, характеристикой. Наблюдаемое может быть связано с локальными напряжениями, возникающими при магнитном превращении карбидных фаз в высокохромистом чугуне. Оно сопровождается явлением магнитострикции, при котором происходит формирование локально направленных напряжений (до 696 МПа) с формированием субзерен в карбидной фазе, что сопровождается изгибом кривых термического расширения, некоторым снижением предела прочности и более существенным коэффициентом линейного расширения (до 20\% при доле карбидной фазы не менее 30\%) [5]. При этом вокруг отдельных границ карбидной фазы (определяется направлением магнитного момента) формируются локальные деформационные зоны, способствующие распаду остаточного аустенита. Для определения существенности этого эффекта необходимо оценить возможные структурные изменения, как в карбидных фазах, так и в матрице, вносящие существенный вклад в уровень потребительских свойств и их стабильность при эксплуатации.

Ранее были исследованы различные подходы [7] для выявления фазового состава высокохромистых сплавов для прокатных валков, которые базировались на рентгеноструктурном анализе, оптической и электронной микроскопии, оценке микротвердости, а также термодинамической оценке выделения различных типов карбидов в высокохромистом чугуне. Каждый из перечисленных методов не дает полного представления о процессах структурообразования, которые имеют место при кристаллизации массивных отливок, их термообработке, а также не позволяют оценить взаимосвязь фаз, что обеспечит определение оптимальных параметров технологического процесса и необходимую их стабильность при эксплуатации.

Исходя из этого, целью настоящих исследований явилось изучение особенностей структурообразования при магнитном превращении высокохромистого чугуна, с оценкой степени неоднородности фаз, их взаимосвязи и развитии диффузионных процессов.

\section{2. Объекты и методы исследований}

Исследования проводили сопоставительно на пробах, отобранных от прокатных валков (торцевого кольца бочки) до и после обработки в интервале температур магнитного превращения карбидных фаз $\left(t=350-500^{\circ} \mathrm{C}\right.$ в течение $\sim 6$ ч). Химический состав исследуемого материала валка (исполнения ЛПХ $18 \mathrm{Hд),} \mathrm{\% ,} \mathrm{2.72-2.86} \mathrm{С,}$ до $18 \mathrm{Cr}$, до $0.24 \mathrm{~V}$ и до $1.5 \mathrm{Ni}$. Образцы для исследований механически обрабатывали с последующим травлением в $4 \%$ растворе $\mathrm{HNO}_{3}$ в этиловом спирте. Структурные изменения оценивали сканирующим электронным микроскопом (SEM) JEOL JSM-6390LV.

Согласно полученным ранее данным [7,8], основными фазами такого чугуна являются $\mathrm{Me}_{7} \mathrm{C}_{3}$, $\mathrm{Me}_{23} \mathrm{C}_{6}, \mathrm{Me}_{3} \mathrm{C}, \alpha$-Fe и $\gamma$-Fe. Такие чугуны имеют и эвтектику типа тонких розеток, состоящих из карбида $\mathrm{Me}_{7} \mathrm{C}_{3}$ и $\gamma$-Fe. Для выявления доли этих фаз и их сочетаний (взаимосвязи) использовали разработанный метод оптико-математического их описания по фотографиям 
металлографических изображений, которые дают представление о степени локальной и общей неоднородности в распределении фаз и степени их стабильности.

Предложенный метод исследования основан на гидродинамических аналогиях с применением уравнений Навье-Стокса, происходящих при формировании фаз (диссипация энергии в результате диффузионных процессов) [9,10]. Оценку производили на основе разработанной компьютерной программы, согласно расположению вычисляемых значений, на изображении металлографической структуры в цифровом формате . $b m p$, поделенном на фрагменты размером $3 \times 3$ пикселя. В каждой точке с координатами $(x, y)$ металлографического изображения вычисляли условный цвет, задаваемый значением лапласиана функции $C(x, y)$, при помощи которого описывали диссипацию энергии [11] в процессе структурообразования:

$$
L(x, y) \equiv \Delta C(x, y)=\frac{\partial^{2} C(x, y)}{\partial x^{2}}+\frac{\partial^{2} C(x, y)}{\partial y^{2}} .
$$

$C(x, y)$ в конечно-разностном представлении будет иметь вид матрицы $C_{i j}$ размером $3 \times 3$ пикселя:

$$
C_{i j}=\left(\begin{array}{ccc}
c_{i-1, j-1} & c_{i-1, j} & c_{i-1, j+1} \\
c_{i, j-1} & c_{i j} & c_{i, j+1} \\
c_{i+1, j-1} & c_{i+1, j} & c_{i+1, j+1}
\end{array}\right) .
$$

Обработку такой матрицы выполняли путем последовательного сканирования каждого пикселя, задавая его как среднюю точку, находящуюся внутри фрагмента заданного размера $(3 \times 3)$. В качестве координаты принимали пиксель изображения (относительно центрального элемента $C_{i j}: i-$ номер строки, $j-$ номер столбца). Где $C_{i j}-$ код цвета в заданном цифровом формате. Конечно-разностное представление лапласиана $L_{i j}(1)$ для каждой точки анализируемого фрагмента изображения имело вид:

$$
L_{i j}=\frac{\Delta^{2} c}{\Delta x^{2}}+\frac{\Delta^{2} c}{\Delta y^{2}}=c_{i, j-1}+c_{i-1, j}+c_{i, j+1}+c_{i+1, j}-4 c_{i, j},
$$

где шаг по координатам на цифровом изображении $\Delta x=\Delta y=1$.

На основании этого, разработан новый многоступенчатый подход анализа структурного состояния в легированных чугунах, в результате кристаллизации и под воздействием явления магнитострикции карбидных фаз, где в качестве критерия оценки степени формируемой локальной неоднородности структуры вокруг и внутри карбидов, использовали параметр изменчивости [12]. Под изменчивостью понимали диффузию в фазах химических компонентов. Изменчивость состава, оцениваемую в одной конкретной точке фазы выбранного фрагмента изображения, задавали соотношением числа совпадений условного цвета средней точки с цветами окружающих ее точек к общему числу пикселей.

Для оценки степени неоднородности структуры в локальных зонах, определяющих разброс концентраций компонентов в фазах, проводили статистический анализ гистограмм распределения условных цветов и изменчивости фаз в заданных фрагментах изображения, которые рассчитывали с использованием распределения Пирсона. Подробно методика оптикоматематического описания фаз приведена в работах $[10,12]$, согласно которой при описаниях типов фаз и их доли была предложена следующая кодировка интервалов условных цветов на изображении микроструктуры и их цифрового обозначения. Красный цвет - карбид $\mathrm{Me}_{7} \mathrm{C}_{3}$ (16); темно красный - карбид $\mathrm{Me}_{23} \mathrm{C}_{6}$ (15); черный цвет - карбид $\mathrm{Me}_{3} \mathrm{C}$ (11); желтый - (А) аустенит (10); голубой - (Ф1) феррит без дефектов, ненасыщенный углеродом (1); белый (Ф5) феррит с дефектами (дислокациями с разной плотностью) с повышенной концентрацией углерода (5); синий - (Ф6) феррит, максимально насыщенный этим компонентом (6). Различие в концентрации углерода в феррите вызвано диффузионными процессами.

На Рис. 1 и S1 (дополнительный материал) приведены SEM фотографии структур высокохромистого чугуна прокатных валков, которые соответствуют фазовому составу до $(\mathrm{a}, \mathrm{b}, \mathrm{c})$ и после $(\mathrm{d}, \mathrm{e}, \mathrm{f})$ их описания оптикоматематическим методом (изменчивость выявленных сочетаний групп фаз). На Рис. 1 структуры (a,b,c) соответствуют литому состоянию, а на Рис. S1 (дополнительный материал), структуры $(\mathrm{a}, \mathrm{b})$ - после обработки в интервале температур магнитного превращения карбидов разного типа (350 и $\left.450-500^{\circ} \mathrm{C}\right)$. Время выдержки на протяжении 6 ч. Этим обеспечили регулируемое охлаждение валка при кристаллизации в форме. Последующее охлаждение осуществляли в кессоне в течение 76 ч.

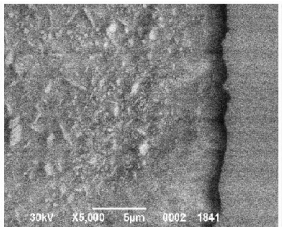

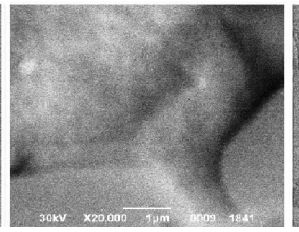

b

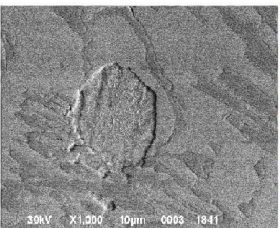

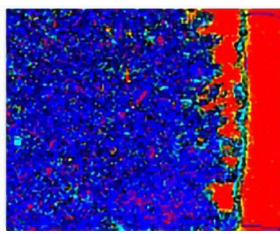

d

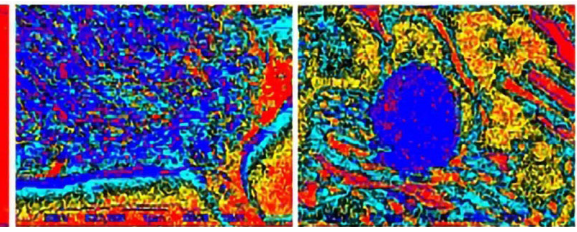

f

Pис. 1. (Color online) Распределение фаз в рабочем слое валка из высокохромистого чугуна: SEM фотографии (сигнал BEC) сплавов 1-3 литого состояния (a, b, c) и изменчивость выявленных сочетаний групп фаз их составляющих (d, e, f).

Fig. 1. (Color online) Phase distribution of a high-chromium cast iron roll in the working layer: SEM photographs (signal BEC) of the alloy $1-3$ of the cast state $(a, b, c)$ and the variability of the revealed combinations of components phase groups $(a, b, c)$. 


\section{3. Результаты и обсуждение}

При традиционных методах анализа не представляется возможным надежно оценить, как долю формируемых фаз, так и их тип. Удается определить лишь суммарное соотношение карбидов и матрицы, а также частично (для более крупных зерен) локальное содержание компонентов микрорентгеноспектральным методом.

На приведенных фотографиях структур литого состояния (Рис. 1а) видно, что у границы с карбидной фазой выявлены включения, которые несколько утончаются вглубь зерна матричной фазы, то есть это дает основание предположить о диффузии углерода из карбидной фазы. В этом случае у границы карбидной фазы формируется тонкая однородная зона, а затем отмечается интенсификация дробления матричной фазы. Иная картина выявлена на Рис. 1с, где по центру фотографии выявлено светлое зерно феррита с выделениями. Кроме того, четко проявляются карбиды (темного цвета), а границы матричной фазы выглядят более светлыми.

Матричная фаза отличается различными оттенками. Если учитывать результаты термодинамической оценки [7], то это могут быть фазы $\alpha$-Fе или $\gamma$-Fe. Из Рис. 1d после оцифровки видно, что граница карбидной фазы $\mathrm{Me}_{7} \mathrm{C}_{3}$ состоит из аустенитной, карбидной $\left(\mathrm{Me}_{3} \mathrm{C}\right)$ и чистой ферритной (Ф1) прослойки. Это характерно не только для массивных включений $\mathrm{Me}_{7} \mathrm{C}_{3}$, но и для более мелких таких выделений. Ферритная составляющая (синий цвет Ф6) характеризуется формированием ячеистой структуры, которую, в основном, составляют карбиды цементитного типа, а также феррит Ф1 и, в меньшей степени, насыщенный углеродом - Ф6. Одновременно по телу субзерен отмечаются отдельные выделения карбидов $\mathrm{Me}_{23} \mathrm{C}_{6}$ (темно-красный цвет). Поэтому такой феррит отличается особенно изменчивым и неоднородным составом. Изображение на Рис. 1е характеризуется еще большей неоднородностью, как границ зерен (карбид-феррит), так и ферритной составляющей. Границы карбидных включений $\mathrm{Me}_{7} \mathrm{C}_{3}$ состоят из неоднородных зон с этой фазой, а также включений $\mathrm{Me}_{3} \mathrm{C}$, Ф1 и Ф6 и $\mathrm{Me}_{23} \mathrm{C}_{6}$. В этом случае ферритное зерно Ф6 включает текстурированные из всех перечисленных фаз субзерна. Можно предположить (пояснения к вопросу стабильности карбида $\mathrm{Me}_{7} \mathrm{C}_{3}$, дополнительный материал), что такая структура является результатом диффузии при распаде первичного карбида $\mathrm{Me}_{7} \mathrm{C}_{3}$ (красный цвет), следы которого отмечаются в локальной зоне (параллельно расположены). Такое предположение подтверждает и Рис. 1f, где тонкие карбиды (типа «стрел»), входящие в эвтектику, частично дробятся и на этом месте выявляются участки с карбидами типа $\mathrm{Me}_{3} \mathrm{C}$ (черный цвет) и аустенит (желтый). Ферритное зерно Ф6 (синий цвет) характеризуется слабо выраженной субструктурой, сформированной выделениями $\mathrm{Me}_{23} \mathrm{C}_{6}$. Такой тип карбидной фазы (темно-красный цвет) выявляется как на концах тонких карбидных включений $\mathrm{Me}_{7} \mathrm{C}_{3}$, так и формирует границу устойчивой части этой фазы. В аустените отмечено выделение мелких карбидов $\mathrm{Me}_{23} \mathrm{C}_{6}$ и $\mathrm{Me}_{3} \mathrm{C}$. При этом, фаза цементитного типа в большей мере выделяется по границам аустенитных зерен.
Для сопоставления анализировали изменчивость структуры после магнитного превращения карбидных фаз. На Рис. S1 (дополнительный материал) отражены локальные структурные изменения по сравнению с литым состоянием. При обработке в интервале магнитного превращения, на SEM снимках (Рис. S1a) более четко проявляются границы карбидных зерен. Одновременно, такие включения карбида имеют и не четко выраженные границы более светлого цвета. Крупное светлое зерно феррита по центру характеризуется более мелкими и тонкими выделениями, чем на Рис. 1a. Границы этого зерна, в ряде зон с карбидной фазой, также имеют светлый цвет. Выявить какие-либо другие фазы и их расположение, долю по традиционным методам не представляется возможным. На Рис. S1b показано, что вокруг спецкарбида $\mathrm{Me}_{7} \mathrm{C}_{3}$ происходит интенсивный распад остаточного аустенита, который проявляется в виде широкой каймы темного и светлого цветов, а ферритная фаза имеет текстурированное строение.

После оптико-математической обработки выявлена отличительная картина в распределении фаз относительно литого состояния (Рис. S1d,e). В этом случае границы субзерен в феррите Ф6 (синего цвета) более четко декорированы карбидом цементитного типа $\mathrm{Me}_{3} \mathrm{C}$ (черный цвет), а также ферритом Ф5 (белый цвет) и Ф6. Кроме того, во фрагментах субзерен и по их границам выявлены отдельные карбиды $\mathrm{Me}_{23} \mathrm{C}_{6}$. Что касается карбидных фаз $\mathrm{Me}_{7} \mathrm{C}_{3}$, то наиболее стабильная их часть ограничена темно-красным цветом, соответствующим карбиду $\mathrm{Me}_{23} \mathrm{C}_{6}$.

Нестабильность карбидов $\mathrm{Me}_{7} \mathrm{C}_{3}$, уже при кристаллизации, может быть объяснена двумя причинами. Первая - принятая технология их литья центробежным методом, когда после заливки и кристаллизации рабочего слоя осуществляют порционный ввод металла сердцевины, при котором не подплавляется уже затвердевший, однако, происходит его циклический подогрев, приводящий к разрушению тонкой эвтектики $\mathrm{Me}_{7} \mathrm{C}_{3}+\gamma$-Fe. Кроме того, такой циклический подогрев при кристаллизации может оказывать влияние и на дестабилизацию границ отдельных зерен карбидов. Вторая причина дестабилизации таких карбидов может быть связана с длительной выдержкой отливки в кессоне (специальной камере) для медленного охлаждения отливки продолжительностью 76 ч. По всей вероятности, такое объяснение является правдоподобным в связи с тем, что выполненная проверка аналогичного распада карбидной фазы в тонкостенных отливках при быстрой их кристаллизации не выявила картины такого структурообразования.

На рассмотренных фотографиях были исследованы локальные изменения структурообразования в сравнительных вариантах, которые их определяют. Представляет интерес общая информация об изменчивости фазового состава. Для этого провели аналогичный сопоставительный анализ на фотографиях микроструктур при меньших увеличениях ×200 (Рис. S2, дополнительный материал, структуры 6 и 7).

На микрошлифах литого металла (Рис. S2a) выявляется структура тонких включений карбидов, а также 
зерен феррита, которые, в большей мере, имеют одинаковый белый цвет. Структура остальной матрицы, в том числе и темные зерна, плохо идентифицируется.

При обработке такого чугуна в интервале магнитного превращения (Рис. S2b) существенно возрастает доля ферритных зерен, которые имеют различный оттенок от белого до серого. Два различных оттенка этой фазы можно наблюдать и в одном зерне. Тонкие включения карбидов дробятся. Основная матрица металла также становится более раздробленной по сравнению с литым состоянием.

Результат оптико-математического описания структуры иллюстрирует Рис. S2 d, е, дающий наиболее полное представление об изменчивости и распределении фаз, а также схеме их взаимодействия при литье (см. Рис. S2d) и магнитном превращении (см. Рис. S2e). Если в первом случае имеет место беспорядочное расположение фаз на фоне Ф6 (синий цвет), то во втором - формируется упорядоченная структура субзерен, границы которой утолщены и включают цементит (основная составляющая), значительную долю карбида $\mathrm{Me}_{23} \mathrm{C}_{6}$ и существенно в меньшем количестве выделяются Ф1, Ф5 и аустенит - голубой, белый и желтый цвета соответственно. Такие изменения происходят на основе частичного распада карбидной фазы $\mathrm{Me}_{7} \mathrm{C}_{3}$, остаточного аустенита и уменьшения доли Ф1. Кроме того, тонкие иглы карбидов эвтектики распадаются одновременно с аустенитом. При этом, на фотографии микроструктуры сохраняется розеточный рельеф эвтектики, а обработка оптико-математическим методом этой эвтектики не выявила, в таких зонах зафиксировано появление значительной доли карбидов типа $\mathrm{Me}_{3} \mathrm{C}$ и существенно меньшей $-\mathrm{Me}_{23} \mathrm{C}_{6}$, Ф5 и Ф6, а также практически полное отсутствие аустенита.

Учитывая полученную информацию об изменчивости структурообразования и его несоответствию металлографическому изображению, выполнили количественную оценку изменения фазового состава (Табл. S1, дополнительный материал). Приведены только выявленные интервалы условных цветов, соответствующие фазам в отливках, с номерами $1,5,6$, $10,11,15$ и 16 [4].
Из приведенных данных видно, что существуют стабильные закономерности изменений доли фаз, как на локальном уровне, (Рис. 1 и S1, дополнительный материал), так и более общем, (Рис. S2, дополнительный материал), согласно фотографиям микроструктур, при увеличении $\times 200$.

Карбид $\mathrm{Me}_{7} \mathrm{C}_{3}$ и аустенит (А) заметно распадаются. Это подтверждают результаты оценки изменчивости фаз (условных цветов).

Детальным анализом установлено (см. Табл. S1, дополнительный материал), что литое состояние при локальной оценке доли фаз отличается значительной неоднородностью в их распределении. Так, это в большей мере относится к ферриту (Ф5), аустениту (А), карбидам $\mathrm{Me}_{3} \mathrm{C}$ и $\mathrm{Me}_{7} \mathrm{C}_{3}$. После обработки в интервале магнитного превращения карбидов возрастает неоднородность в распределении доли $Ф 1$ и его площадь на фотографии уменьшается. Заметно возрастает и становится более стабильной доля ферритных фаз (Ф5 и Ф6), насыщенных углеродом. Средняя доля аустенита и карбида $\mathrm{Me}_{7} \mathrm{C}_{3}$ снижается. Вместе с тем, неоднородность в локальном распределении аустенита сохраняется.

Из обработанных в цифровом формате изображений, отражающих площадь расположения фаз, видно, что общие фотографии микроструктур отражают те же закономерности в их изменчивости, что и локальные оценки. Это также хорошо иллюстрируют и изображения микроструктур в цвете (см. Рис. 1, S1, дополнительный материал).

Учитывая тот факт, что при локальном и общем анализе фаз, имеет место не только одинаковый характер их изменчивости, но и близкая доля их составляющих, для большей информативности в Табл. 1 объединили однотипные показания, полученные при оптикоматематическом анализе.

Из Табл. 1 видно, что общая изменчивость доли фаз, независимо от типа процесса обработки в интервале температур магнитного превращения карбидов, составляет $46.6 \%$. При этом существенно уменьшаются доли $\mathrm{Me}_{7} \mathrm{C}_{3}$ и аустенита (А) на $9.9 \%$ и $8.1 \%$ соответственно. Они распадаются, в большей мере, с образованием Ме $\mathrm{C}$ и Ф5, что соответствует $10.6 \%$ и $7.1 \%$.

табл. 1. Сопоставительный анализ средней изменчивости доли фаз в высокохромистом чугуне.

Table 1. Comparative analysis of the average variability of the proportion of phases in high-chromium cast iron.

\begin{tabular}{|c|c|c|c|c|c|c|c|}
\hline \multirow[t]{2}{*}{$\begin{array}{l}\text { Способ получения } \\
\text { Production method }\end{array}$} & \multicolumn{7}{|c|}{$\begin{array}{c}\text { Доля фаз, \%* и ее изменчивость } \\
\text { The proportion of phases, per cent, \%* and its variability }\end{array}$} \\
\hline & $\Phi 1 /$ F1 & $\Phi 5 /$ F5 & Ф6 / F6 & A & $\mathrm{Me}_{3} \mathrm{C}$ & $\mathrm{Me}_{23} \mathrm{C}_{6}$ & $\mathrm{Me}_{7} \mathrm{C}_{3}$ \\
\hline Литое состояние / as-cast & 25.1 & 1.3 & 11.1 & 17.2 & 11.8 & 3.4 & 30.1 \\
\hline $\mathrm{TO}^{* *} / \mathrm{HT}$ & 19.8 & 8.4 & 14.5 & 9.1 & 22.4 & 5.6 & 20.2 \\
\hline $\begin{array}{l}\text { Изменение в содержании доли фаз } \\
\text { Change in proportion of phases content }\end{array}$ & -5.3 & +7.1 & +3.4 & -8.1 & +10.6 & +2.2 & -9.9 \\
\hline
\end{tabular}

*знак «-» означает уменьшение доли фазы; «+» - ее повышение; изменчивость суммарной доли фаз составляет (без учета знака) $46.6 \%$.

**ТО - обработка в интервале температур магнитного превращения карбидов.

* «-» sign corresponds to decrease of phase share; «+» sign corresponds to its increase; variability of cumulative phase content (ignoring sign): $46.6 \%$.

${ }^{* *} \mathrm{HT}-$ processing in the interval of magnetic transformation of carbides. 
Для установления взаимосвязи между фазами дополнительно исследовали изменчивость различных их сочетаний. Согласно схеме (2) вычисляемых значений, возможны такие сочетания $\Phi+\mathrm{A} ; \Phi+\mathrm{K} ; \mathrm{A}+\mathrm{K}$; $\Phi+\mathrm{A}+\mathrm{K}$, где буквой К обозначили общую группу карбидных фаз, а $\Phi-$ ферритных, выявленных в исследуемых фрагментах изображений $(3 \times 3$ пикселя). В этом случае также сопоставительно анализировали рассмотренные выше варианты литого состояния и обработки в интервале температур магнитного превращения карбидных фаз (ТО). Результаты расчетов приведены в Табл. S2 (дополнительный материал).

Анализируя результаты Табл. S2 (дополнительный материал), можно заключить, что нагрев и выдержка чугуна при температуре магнитного превращения карбидов сопровождается не только структурными изменениями как внутри зерен феррита (формирование субструктуры с выделением карбидов $\mathrm{Me}_{23} \mathrm{C}_{6}$ и $\mathrm{Me}_{3} \mathrm{C}$ ), так и увеличением связей между фазами. Такие связи мало зависят от способа обработки и степени локальности, поскольку имеют близкие показатели. Исключение лишь составляет остаточный аустенит, доля которого уменьшается, и в результате существенно снижается количество его связей с другими фазами.

Из полученных данных следует, что изменчивость фаз по их сочетанию, выявленная оптико-математическим методом, не зависит от увеличения.

В выполненных исследованиях получено новое представление о фазовом составе высокохромистого чугуна, его изменчивости при магнитном превращении карбидных фаз, распаде остаточного аустенита. Такой подход может быть использован при разработке и прогнозировании стабильности свойств и эксплуатационной стойкости. Метод может быть эффективен и для моделирования новых технологических процессов производства и упрочнения сплавов с гетерогенной структурой, неоднородным распределением фаз и развитием диффузионных процессов при эксплуатации.

\section{4. Заключение}

Разработан новый подход к выявлению фазового состава в гетерогенном высокохромистом чугуне. Выявлены особенности структурообразования массивных отливок (до 20 т) при их кристаллизации и обработке интервале температур магнитного превращения карбидных фаз (явление магнитострикции). Оценена изменчивость фаз и их взаимосвязь при литье и термообработке.

Показано, что фотографии металлографических изображений не позволяют надежно оценить фазовый состав сплава, поскольку первичный рельеф изображения после их кристаллизации сохраняется, а по существу в нем происходит частичный распад фаз с формированием их различных сочетаний. Показана возможность точной качественной и количественной идентификации формируемых фаз в литом и термообработанном состоянии в многофазном гетерогенном сплаве - высокохромистом чугуне отливок большой массы. Предложен новый подход к оценке структурообразования в многофазном сплаве с использованием оптико-математического метода описания металлографических изображений.

Дополнительный материал/Supplementary Material. Электронная версия статьи содержит дополнительныи материал, доступный безвозмездно на сайте журнала (lettersonmaterials.com)./The online version of this paper contains supplementary material available free of charge at the journal's Web site (lettersonmaterials.com).

\section{Литература/References}

1. V.Z. Kutzova et al. Metaloznavstvo ta termichna obrobka metaliv. 1, 35 (2008). (in Russian) [В.3. Куцова и др. МиТОМ. 1, 35 (2008).]

2. M. A. Guitar et al. JMEP. 27 (8), 3877 (2018). Crossref

3. E. Karantzalis, A. Lekatou et al. International Journal of Cast Metals Research. 22 (6), 448 (2009). Crossref

4. T. S. Skoblo et al. Steel in Translation. 43 (9), 603 (2013). Crossref

5. T.S. Skoblo et al. High Carbon Alloy Rolling Rolls (Ed. by T.S. Skoblo). Moscow, Metallurgiya (1994) 336 p. (in Russian) [T.C. Скобло и др. Прокатные валки из высокоуглеродистых сплавов (Под ред. Т. С. Скобло). Москва, Металлургия (1994) 336 с.]

6. Patent UA № 105761, 11.04.2016. (in Ukrainian) [Патент Украины № 105761, 11.04.2016].

7. T.S. Skoblo et al. Production and use of casting rollers: Handbook (Ed. by T.S. Skoblo). CD No. 1, Kharkiv (2013) 572 p. (in Russian) [Т. С. Скобло и др. Производство и применение прокатных валков: Справочник (Под ред. Т. С. Скобло). СD№ 1, Харьков (2013) 572 c.]

8. I.I. Tsypin. White wear-resistant cast irons. Structure and properties. Moscow, Metallurgiya (1983) 176 p. (in Russian) [И. И. Цыпин Белые износостойкие чугуны. Структура и свойства. Москва, Металлургия (1983) 176 c.]

9. P.J. Roache. Fundamentals of Computational Fluid Dynamics. Hermosa Pub (1998) 648 p.

10. T. S. Skoblo et al. Steel in Translation. 42 (3), 261 (2012). Crossref

11. N.A. Slezkin. Viscous Incompressible Fluid Dynamics. Moscow, Gostekhizdat (1955) 520 p. (in Russian) [Н.А. Слезкин. Динамика вязкой несжимаемой жидкости. Москва, Гостехиздат (1955) 520 с.]

12. T.S. Skoblo et al. Industrial laboratory diagnostics of materials. 83 (5), 27 (2017). (in Russian) [Т. С. Скобло и др. Заводская лаборатория. Диагностика материалов. 83 (5), 27 (2017).] 